\title{
COMMISSION 48: HIGH ENERGY ASTROPHYSICS (ASTROPHYSIQUE DE GRANDE ÉNERGIE)
}

\author{
Report of Meetings
}

ACting PRESIDENT: M. J. Rees.

A business meeting of Commission 48 was held on Saturday, 25 August. After considering the proposed list of officers and new members of the Commission, there was a short discussion of the Executive Committee's request that the Commission should formulate a list of 'scientific priorities' within its field of interest. It was felt that Commission 48 covered such a broad range of topics that this task was neither feasible nor desirable. Consideration was also given to the optimal form of the Commission's contribution to the next edition of 'Reports on Astronomy' It was agreed that the Commission should produce only a very short and general Report, supplemented by a selected list of review articles, conference proceedings, etc., wherein up-to-date reviews of topics in high energy astrophysics could be found. After the conclusion of the business, the following scientific papers were presented:

L. E. Peterson: Gamma-Ray Bursts of Cosmic Origin.

J. V. Jelley (read by M. J. Rees): Searches for Microwave Pulses from Supernovae.

E. E. Salpeter: Comets around Neutron Stars, and Their Possible Observational Consequences.

A further scientific session of the Commission was held on 29 August, at which the following papers were read:

M. P. Savedoff: New Methods for Detecting Rapid Optical Variables.

F. D. Drake: Pulsar Observations with High Time and Spectral Resolution.

L. E. Peterson: Gamma-Ray Background Measurements from Apollo 15 and 16.

R. C. Catura: Soft X-Ray Observations of M 87.

D. G. Wentzel: Instabilities in the Propagation of Low Frequency Waves.

F. Meyer: Gravitational Wave Experiments.

Commission 48 also participated, with other Commissions, in a session on close binary systems and $\mathrm{X}$-ray sources. 